\title{
Metformin and berberine, two versatile drugs in treatment of common metabolic diseases
}

\author{
Haoran Wang ${ }^{1, *}$, Chen Zhu ${ }^{1, *}$, Ying Ying ${ }^{2}$, Lingyu Luo ${ }^{1}$, Deqiang Huang ${ }^{1}$ and Zhijun \\ Luo $^{2,3}$ \\ ${ }^{1}$ Department of Gastroenterology, Research Institute of Digestive Diseases, The First Hospital of Nanchang University, \\ Nanchang, China \\ 2 Jiangxi Provincial Key Laboratory of Tumour Pathogenesis and Molecular Pathology, Department of Pathophysiology, School \\ of Basic Medical Sciences, Nanchang University, Nanchang, China \\ ${ }^{3}$ Department of Biochemistry, Boston University School of Medicine, Boston, MA, USA \\ *These authors contributed equally to this work
}

Correspondence to: Deqiang Huang, email: dqhuang0515@163.com

Zhijun Luo, email: zluo@bu.edu

Keywords: metformin, berberine, metabolic diseases, tumour

Received: July 19, 2017 Accepted: August 17, $2017 \quad$ Published: September 11, 2017

Copyright: Wang et al. This is an open-access article distributed under the terms of the Creative Commons Attribution License 3.0 (CC BY 3.0), which permits unrestricted use, distribution, and reproduction in any medium, provided the original author and source are credited.

\section{ABSTRACT}

Metformin has been used as a glucose lowering drug for several centuries and is now a first-line drug for type 2 diabetes mellitus (T2DM). Since the discovery that it activates AMP-activated protein kinase (AMPK) and reduces risk of cancer, metformin has drawn great attentions. Another drug, berberine, extracted from berberis vulgaris $L$. (root), was an ancient herbal medicine in treating diarrhea. Ongoing experimental and clinical studies have illuminated great potential of berberine in regulation of glucose and lipid homeostasis, cancer growth and inflammation. Furthermore, the lipid lowering effect of berberine is comparable to those conventional lipid drugs but with low toxicity. Therefore, it is right time to transform beneficial effects of berberine into therapeutic practice. Metformin and berberine share many features in actions despite different structure and both could be excellent drugs in treating T2DM, obesity, cardiac diseases, tumour, as well as inflammation. Since these disorders are often connected and comprise common pathogenic factors that could be targeted by the two drugs, understanding their actions can give us rationale for expansion of their clinical uses.

\section{INTRODUCTION}

The discovery of metformin dates back to 17 th century. Galega officinalis L., also known as the French lilac, was used as a herbal remedy to relieve the intense urination caused by the diabetes mellitus in medieval times [1]. The guanides are rich in French lilac and essential compounds in lowering blood glucose, which led to development of three biguanides, metformin, phenformn, and buformin (Figure 1). Among them metformin was found to be the most useful drug because of its low toxicity. It was first synthesized in 1922, but approved for treatment of diabetes in Europe until 1950s and by FDA in USA in 1994 [2]. Phenformin and buformin were abandoned in 1970s for intolerable side effects such as high frequency of lactic acidosis and increased mortality. The United Kingdom Prospective Diabetes Study (UKPDS) has revealed that metformin is the only oral anti-hyperglycemic agent that reduces macrovascular complications in patients with T2DM [3]. Further clinical investigations and practice have recommended it as a first line drug for T2DM. Moreover, it has been expanded to treatment of other diseases such as obesity and tumour.

Berberine was used in Chinese and Ayurvedic medicine around $3000 \mathrm{BC}$ (Figure 1). The plant barberry (berberis vulgaris) was a herbal medicine in treating diarrhea [4] and dysentery [5]. Its constituents were then 
extracted, among which berberine was the most active alkaloid [6]. Berberine belongs to the structural class of protoberberines and is also present in the barks of other plant species including Hydrastis Canadensis L., Coptis chinensis Franch, Arcangelisia flava (L.) Meer., B. aquifolium Pursh. and B. aristata D.C. [7], although the extraction purity of berberine varies among plants. Up to date, berberine has been used as a non-prescription drug in clinics for diarrhea, dysentery, stomatitis [8] and hepatitis [9]. Numerous researches have been carried out to unravel its other pharmacological and therapeutic effects, especially on T2DM, lipid metabolism and tumour.

Nowadays, diabetes has become one of the most common public health issues due to increased prevalence, morbidity and mortality caused by complications [10]. Tremendous amount of efforts has been casted to identify effective agents with low toxicity. Although many studies have shown that berberine exerts hypoglycemic actions similarly to metformin, it has not been extensively used in treating diabetes. Furthermore, the potentials of both drugs in obesity and tumour management have attracted a lot of research interests. Hence, in this review, we will summarize recent progresses in studies on mechanisms of their actions and compare their utilities in treatment of several common and interconnected diseases such as diabetes, obesity, cardiovascular diseases, and tumours as well as inflammation.

\section{ANTI-DIABETIC ACTION}

Diabetes mellitus is a chronic, progressive metabolic disorder. There are two categories, type 1 diabetes mellitus (T1DM) and type 2 diabetes mellitus (T2DM), of which T2DM comprises almost 90\% cases [11]. While T1DM

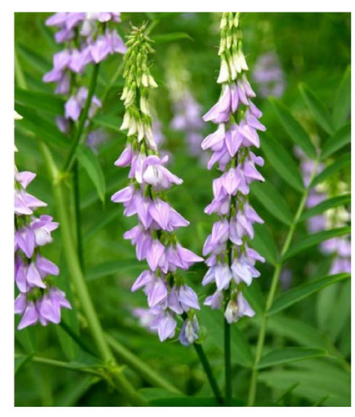

Galega officinalis<smiles>CN(C)C(=N)NC(=N)N</smiles><smiles>CCCCNC(=N)NC(=N)N</smiles>

Metformin
Buformin

is an early onset autoimmune disease that leads to destruction of $\beta$-cells, T2DM exhibits insulin resistance in liver, muscle and adipose at early stages, and eventually $\beta$ cell failure at late stages, which is characterized as non-insulin dependent diabetes mellitus (NIDDM) [12]. The progression of T2DM starts from insulin resistance attributable to genetic and environmental factors [13]. Defects in insulin action at first can be compensated by increased insulin secretion, resulting in hyperinsulinemia, so as to maintain blood glucose homeostasis. Until the secretory function of the $\beta$ cells cannot compensate further declined insulin sensitivity, the overt T2DM develops. In liver, insulin resistance is manifested by excessive production of glucose (gluconeogenesis) in the fasting state and impaired glucose uptake after meal regardless the presence of insulin, while in muscle, insulin resistance exhibits decreased glucose uptake, all of which lead to postprandial hyperglycemia [12, 14-16]. Liver, muscle and $\beta$ cells were initially referred as the triumvirate of T2DM and are the targets of conventional therapies [12]. Later studies have provided evidence that adipose, brain, pancreatic $\alpha$-cells, intestinal cells, and kidney also play important roles in the progression of T2DM [16].

Metformin suppresses hepatic glucose production and stimulates glucose uptake in muscle and adipose, resulting in improvement of hyperglycemia and hyperlipidemia and alleviating non-alcoholic fat liver disease (NAFLD) [17-19]. In addition to enhancing insulin sensitivity in peripheral tissues, metformin can protect $\beta$-islets against lipotoxicity and glucotoxicity to restore insulin secretion $[20,21]$. The first target of metformin identified is the $5^{\prime}$-AMP activated protein kinase (AMPK), although some effects are reported to be mediated through AMPK-independent mechanisms [22-24].

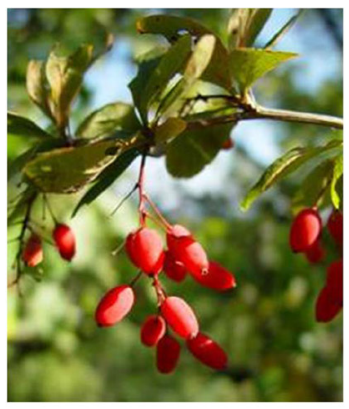

Berberis vulgaris<smiles>N=C(N)NC(=N)NCCc1ccccc1</smiles>

Phenformin<smiles>COc1ccc2cc3[n+](cc2c1OC)CCc1cc2c(cc1-3)OCO2</smiles>

Berberine

Figure 1: Structure of biguanides and berberine. 
The effects of berberine on T2DM was first reported in $1986[25,26]$. Yin et al compared the effects of berberine and metformin [27]. In a three months trial, 36 patients with T2DM were randomly assigned with berberine or metformin. It was found that hypoglycemic effect of berberine is comparable to that of metformin. The level of hemoglobin A1c (HbA1c), fasting and postprandial glucose decreased by $7.5 \%, 6.9 \%$ and $11.1 \%$ respectively at the end of the trial. Similar findings were reported in a clinical study of Zhang et al [28]. A meta-analysis of 21 clinical trials revealed that berberine has therapeutic effects on T2DM, hyperlipidemia and hypertension, comparable to other therapeutic regimes [29]. Studies have indicated that, similarly to metformin, berberine executes its functions by regulating a variety of effectors including AMPK, MAPK, PKC, PPAR $\alpha$, PPAR $\gamma[28,30]$. To be noteworthy, via activation of AMPK, berberine can stimulate glucose uptake in muscle, liver and adipose, and inhibit gluconeogenesis in liver by downregulation of gluconeogenic enzymes (phosphoenolpyruvate carboxyl kinase and glucose-6-phosphatase) [31].

\section{ANTI-OBESITY}

The effect of metformin on body weight and NAFLD has been assessed in a number of studies with inconclusive results. A 10-year follow-up study on patients with T2MD and obesity revealed modest body weight loss in groups treated with metformin, as compared to placebo [32]. However, Seifarth et al showed reduction of body weight in obese individuals without T2DM, in which treatment with metformin for 6 month caused a mean weight loss of $5.8 \pm 7.0 \mathrm{~kg}$, while untreated control group gained $0.8 \pm 3.5 \mathrm{~kg}$ on average [33]. Le and Lomba [34] summarized results of eight studies on the effect of metformin on body weight and NAFLD/NASH and showed no consistent results (with the $50 \%$ to $50 \%$ ratio significance and insignificance), suggesting that more factors should be considered in experimental designs.

Berberine has been shown to be a potential drug to treat obesity by downregulation of adipognesis and lipogenesis. Mice treated with berberine were found to contain shrunk adipocytes [35]. This anti-obese activity is consistent with the finding that berberine significantly decreased sizes and number of lipid droplets in 3T3-L1 adipocytes [36]. Berberine exerts its long-term body weight losing effect through enhancing AMPK-mediated ATGL expression, which increases the basal lipolysis state of triglycerides in adipocytes [36]. In addition, berberine displays an inhibitory effect on proliferation and differentiation of preadipocytes. PPAR $\gamma$ is a crucial transcription factor of adipogenesis and berberine inhibits adipocyte differentiation through $\operatorname{PPAR} \gamma$ and $\mathrm{C} / \mathrm{EBP} \alpha[37,38]$.

Berberine was reported to inhibit cholesterol and triglyceride synthesis in HepG2 cells, a human hepatoma cell line, and primary hepatocytes $[39,40]$. The evidence for the inhibitory effect of berberine on NAFLD comes from rodent animal models that are induced by fat diet [4146]. There is no direct evidence in humans showing the protective effect of berberine on NAFLD, but an indirect clinical investigation suggests that berberine supplement may suppress NAFLD, as it reduces alanine and aspartate transaminase levels in patients with T2DM [47].

\section{CARDIOVASCULAR PROTECTION AGAINST DAMAGE BY HYPERLIPIDEMIA}

Cardiovascular disease (CVD) has become one of the most severe complications of T2DM, an important factor for mortality. Thus, for patients with T2DM, cardiovascular protection is extremely important. In 1998, the UKPDS demonstrated that monotherapy of metformin was correlated to decreased risk of CVD in overweight T2DM patients [48]. Studies have shown that metformin significantly reduces free fatty acid, triglyceride and soluble vascular cell adhesion molecule-1 (sVCAM-1) levels in body, which account for decreases in the risk of CVD [49]. In a 7-year follow-up study, Xu et al assessed the effects of metformin on metabolite profiles and LDL cholesterol (LDL-c) [50]. The results revealed a lower blood level of LDL-c in T2DM patients treated with metformin, compared to other groups. Hyperlipidemia, especially LDL-c, has been proven to be a risk factor of coronary heart diseases [51]. Therefore, metformin can reduce the risk of coronary heart diseases complicated with T2DM.

The documentation of the beneficial effects of berberine on CVD dates back to the 1980s [52]. Intravenous infusion of berberine in 12 patients with heart failure refractory to digitalis and diuretics led to an acute decrease in peripheral resistance and increase in cardiac index. This finding has inspired researchers' interests. Berberine was first reported to lower LDL-c, a risk factor for CVD, by upregulating LDLR gene expression and stability of LDLR mRNA and therefore increasing LDLR-mediated liver clearance [53, 54]. Another study showed that in elderly hypercholesterolemic patients who were statin-intolerant, berberine could ameliorate hypercholesterolemia and plasma LDL-c levels [55].

With regard to the mechanism, it has been reported that berberine modulates LDLR at a post-translational level [56, 57]. In HepG2 cells, berberine causes ubiquitination and degradation of hepatocyte nuclear factor $1 \alpha(\mathrm{HNF} 1 \alpha)$, which is a critical transcription activator of proprotein convertase subtilisin/kexin type 9 (PCSK9), a nature inhibitor of LDLR. PCSK9 binds to the extracellular domain of LDLR, causing its degradation. Thus, LDLR is activated as a result of reduced expression of PCSK9. In addition, berberine lowers blood cholesterol levels through inhibiting intestinal absorption, cholesterol uptake and secretion in enterocyte [58]. The amphipathic 
property of berberine interferes with cholesterol micellarization in the intestinal lumen, thus decreasing absorption. Similar to the effect on micelles, this physicalchemical property may interact with enterocyte membrane, decreasing permeability of cholesterol micelles and in turn the cholesterol uptake. Following micelles entering the enterocytes, re-esterification step is also interfered because berberine downregulates the gene expression of AcetylCoA acetyltransferase 2, leading to decreased secretion of cholesterol from enterocytes into the lymphatics. These results are in accordance with the observations in berberine-fed rats that the levels of total plasma cholesterol, LDL-c and dietary cholesterol absorption rate decreased by $31 \%, 36 \%$ and $45 \%$, respectively [58]. Above all, the lipid lowering effects of berberine sound more attractive than those conventional lipid lowering drugs because of its low toxicity and its pairing with drugs like statins could improve the therapeutic efficacy and life quality of hyperlipidemic patients [29].

\section{ANTI-TUMOUR ACTIVITY}

The effects of metformin on tumour have emerged as a hot topic during the last decade or so [24, 59, 60]. The first seminal report is the retrospective investigation on the incidence of tumour in T2DM patients receiving metformin, which shows $30 \%$ reduction of overall tumour onsets [61]. The T2DM patients with cancers such as lung cancer, pancreatic cancer and breast cancer showed better prognosis when metformin was used as a hypoglycemic drug [62-64]. A plethora of in vitro studies have demonstrated that metformin inhibit tumour cell growth via various mechanisms $[24,60]$. Therein, AMPK plays an important role in mediating the tumour suppressing effect of metformin. First, the liver kinase B1 (LKB1), a dominant upstream kinase of AMPK that phosphorylates Thr-172 in the activation loop, is a tumour suppressor. Loss-of-function mutations of LKB1 have been found in many types of cancer, or its gene is hypermethylated and suppressed if not mutated $[60,65,66]$. Although LKB1 is not activated directly by metformin, it is required for maximal activation of AMPK. As such, the anti-proliferative action of metformin is compromised in tumour/cells lacking LKB1 (Figure 2) [60]. Moreover, it has been reported that metformin induces cytoplasmic translocation of LKB1, enhancing AMPK activation [67]. Second, the AMPK pathway targets many key tumour-promoting signalling pathways, one of which is the mammalian target of rapamycin (mTOR). mTOR is an important protein kinase which regulates protein translation and cell cycle progression. This kinase is bound with accessary proteins such as raptor to form mTOR complex 1 (mTORC1) [68]. GTP-bound Ras homolog enriched in brain (Rheb) is a necessary mTOR activator that is inhibited by tuberous sclerosis complex 1 (TSC1) and tuberous sclerosis complex 2 (TSC2). These two proteins form a GTPase activating protein (GAP) with specificity toward Rheb [69].
In tumour cells bearing activated Akt, TSC2 is inhibited by phosphorylation, leading to an increase in Rheb-GTP and mTOR activation. AMPK inhibits mTOR mainly via two mechanisms, phosphorylation and activation of TSC2, and phosphorylation and inhibition of Raptor. In addition, effector proteins of AMPK implicated in cell growth have increased to a long list [70]. Therefore, the activation of LKB1/AMPK pathway by metformin offers a meaningful strategy for tumour treatment.

Likewise, the antitumor activity of berberine has become increasingly interesting. Up till now, there are more than 600 publications in PubMed by entering "berberine and cancer". Berberine has been shown to exert antitumor effects through multiple routes, for example, suppressing cell proliferation, metastasis and angiogenesis in numerous tumour types, including breast cancer, gastric cancer, melanoma, and hepatoma [71-76]. Studies of Yu et al have shown that berberine can reverse epithelial mesenchymal transition (EMT) and suppress invasion and migration of the mouse melanoma B16 cells by $50.5 \%$ and $67.53 \%$, respectively [73]. Berberine decreases levels of phosphorylated PI3K (p-PI3K), p-AKT and RAR $\alpha$ while increases RAR $\beta$, RAR $\gamma$ and the epithelial marker E-cadherin. Through regulation of $R A R \alpha / \beta$ and the $\mathrm{PI} 3 \mathrm{~K} / \mathrm{AKT}$ signalling pathway, berberine could be used as an adjuvant therapeutic agent to metastatic melanoma that cannot be cured only by surgery. Similar therapeutic potential is also proposed in triple negative basal-like breast cancers, most malignant breast cancer subtype [77-79]. Berberine can target vasodilator-stimulated phosphoprotein, which mediates cell migration and whose elevation level is correlated with poor pathological stage $[71,80]$. In terms of possible role in inhibiting EMT and metastasis of cancer, berberine and metformin seem to have similar effects [81-83].

\section{ANTI-INFLAMMATORY EFFECT}

Nowadays, it is accepted that dysregulation of immunity is involved in diabetes, obesity, cardiovascular diseases and cancer. Infiltration of immune cells such as macrophages and neutrophils to affected tissues, where cytokines are secreted plays important roles in the pathogenesis of the diseases. The anti-inflammatory effect of berberine has been acknowledged for long history. Current investigations have revealed that berberine exerts the anti-inflammatory activities in the intestinal lumen by regulating their transcription and therefore ameliorating proinflammatory cytokine-induced intestinal epithelial damage, which is mediated mainly through activation of AMPK and inhibition of transcription factor activator protein 1 (AP1) and NF- $\kappa \mathrm{B}$ [84]. For example, berberine inhibits mucosal generation of interleukin-8 (IL-8), which is responsible for polymorphonuclear neutrophils infiltration in intestinal lesions of intestine bowel disease (IBD) and ulcerative colitis [85]. Similar effects were observed in metformin. 
Study of Koh et al indicates that metformin inhibits NF$\kappa \mathrm{B}$ activation in intestinal epithelial cells and ameliorates colitis-related carcinogenesis [86]. IBD, colitis and the Crohn's disease are characterized by chronic inflammation caused by infection or autoimmune dysregulation, which result in increased risk of cancer [87]. Furthermore, macrophage infiltration into tumour tissues has been depicted to have a role in tumorigenesis and tumour progression [88]. In light of the anti-tumour activities mentioned above, simultaneous treatment of inflammation and cancer by berberine or metformin may yield a better prognosis and point to a new research area [89].

Obesity-associated insulin resistance and $\beta$ cell dysfunction can induce serious inflammation [90]. Berberine via activation of AMPK can exert an antiinflammatory effect in adipose tissue induced by high fat diet. The obesity is accompanied by a low-grade chronic inflammation state, characterized by infiltration of CD11c+ macrophages or adipose tissue macrophages (ATM) and neutrophils [91-93]. IL-1 $\beta$ and IL-18 as principal inflammatory cytokines released from ATM contribute to the obesity-associated insulin resistance. Berberine improves insulin sensitivity by upregulating autophagic levels in macrophage and inhibiting ATM phenotypic switch to decrease CD11c + population [94, 95]. Likewise, metformin is able to decrease production of nitric oxide, prostaglandin E2 and proinflammatory cytokines (IL-1 $\beta$, IL-6 and tumour necrosis factor (TNF)- $\alpha$ ) through inhibition of NF- $\kappa \mathrm{B}$ activation in macrophages [96]. The anti-inflammation effects of berberine and metformin can inhibit the progress of diseases, which gives better outcomes for patients [97].

\section{MECHANISMS UNDERLYING THE ACTIONS OF METFORMIN AND BERBERINE}

Metformin was first reported to implement its function through activation of AMPK [98]. This occurs via inhibition of complex I in the mitochondrial respiratory chain, leading to an increase in the AMP/ATP ratio and thereby allowing AMP to bind and activate AMPK [99]. In some cases, however, this notion was challenged by two observations. First, hepatic ablation of LKB1 does not abolish the inhibitory effect of metformin on hepatic gluconeogenesis [100]. Second, in vitro studies revealed that the concentration of metformin required for activation of AMPK is greater than that for acute inhibition of gluconeogenesis in hepatocytes [98]. These findings have led to scrutiny of the mechanism underlying inhibition of hepatic gluconeogenesis. Thus, Madiraju et al have demonstrated that metformin inhibits mitochondrial glycerol-3-phosphate dehydrogenase, leading to changes in mitochondrial and cytoplasmic redox states and glucose synthesis [23]. This takes place independently of AMPK activation. In addition, other mechanisms such as AMP-medicated inhibition of adenylate cyclase have

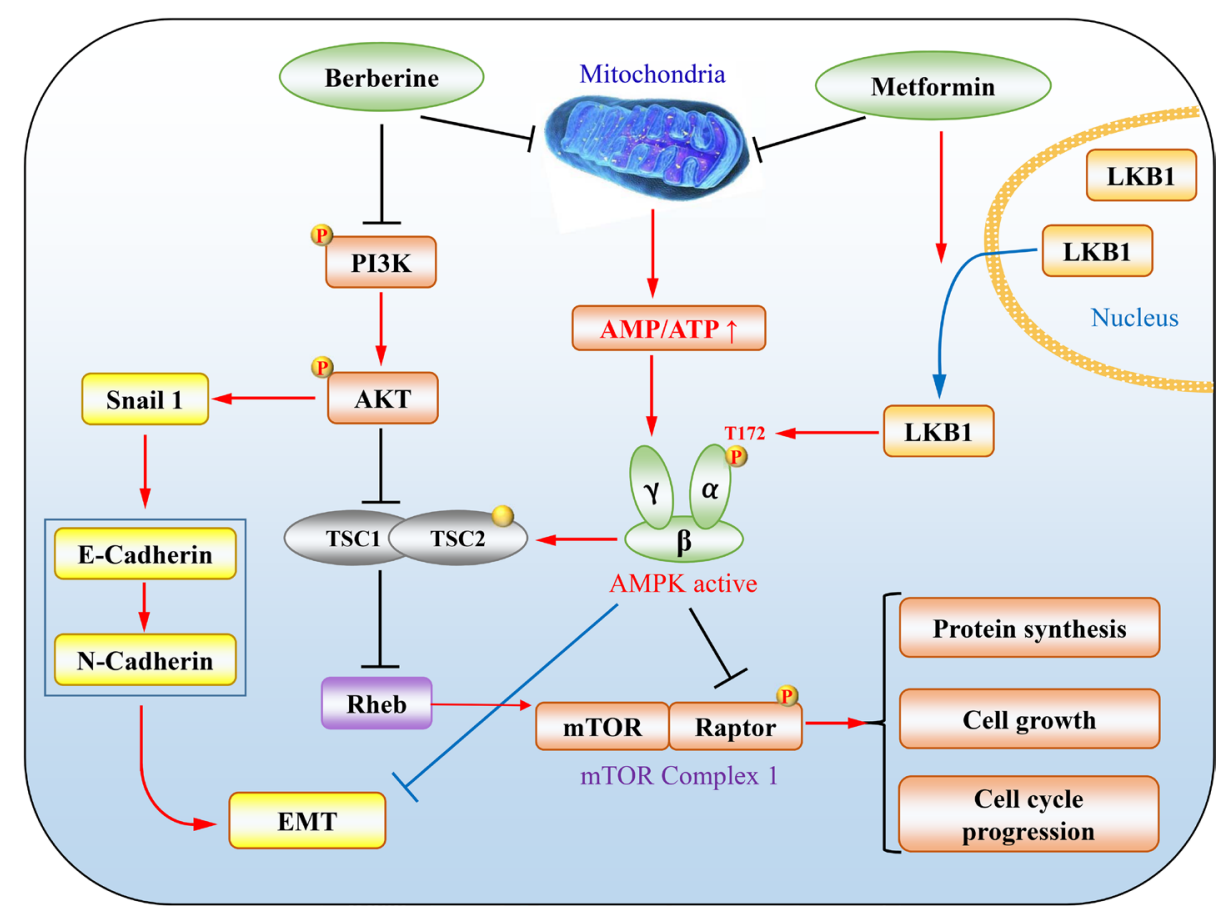

Figure 2: The representative mechanisms underlying tumour suppression by metformin and berberine. (1) LKB1/AMPK/ mTORC1 axis. PI3K/Akt inhibits TSC1/TSC2, leading to increases in Rheb-GTP and mTOR activation. Metformin increases levels of AMP and thus promotes activation of AMPK through LKB1 phosphorylation of T172, which by phosphorylation in turn inhibits raptor and activates the TSC1/TSC2 complex, an GTPase activating protein for Rheb, culminating in inhibition of mTORC1. (2) Both metformin and berberine can attenuate EMT. In addition, berberine activates AMPK to execute cellular functions by a mechanism similarly to metformin. 
been delineated, a mechanism by which metformin inhibits glucagon-induced glucose production in liver, an AMPKindependent action [101]. Which mechanism prevails probably depends on the context and function of specific tissues or cells. Since gluconeogenesis is insignificant in other cells than hepatocytes, it is conceivable many of other actions of metformin is still mediated by AMPK in these cells.

Berberine has been shown to inhibit mitochondrial respiratory complex I, which could lead to the increase of AMP and subsequent AMPK activation [102]. However, a recent report demonstrates that berberine blocks complex I, leading to increases in glucose consumption and lactate release, which is independent of AMPK [103]. This raises an interesting possibility that berberine and metformin may act through similar mechanisms despite different structure and transporters. As inhibition of respiratory chain engenders stress conditions, addition of berberine or metformin could elicit cellular stress responses, such as activation of $\mathrm{p} 38$ and JNK pathways, which might be dependent or independent of AMPK activation. Also, we cannot exclude extra-mitochondrial events evoked by these drugs. It is not clear whether metformin and berberine undertake all actions via the same mechanisms, or some via similar and others different mechanisms.

\section{PHARMACOKINETICS}

Metformin is an excellent drug with good oral bioavailability and pharmacokinetic behaviours. It is usually not metabolized in our body and its half-life is about 5 hours. Fixed forms of drugs are excreted in urine with a renal clearance of $510 \pm 120 \mathrm{ml} / \mathrm{min}$ [104]. Following absorption, metformin is rapidly distributed in various tissues without binding to plasma proteins, and then undergoes hepatic uptake and renal excretion, which are mainly controlled by organic cation transporters (OCTs) $[105,106]$. These transporters manage the influx and efflux of metformin in different tissue cells to maintain steady state concentrations of metformin. OCT1 (SLC22A1) and OCT3 (SLC22A3) are expressed on the basolateral membranes of hepatocytes [107-109] and in skeletal muscle [110-112]. The clearance of metformin is finished by kidney. Metformin is transported into the proximal tubular lining cells by OCT1, OCT2 and OCT3 on basolateral side of renal tubular cells [105]. Then the $\mathrm{H}(+)$ /organic cation antiporters, multidrug and toxin extrusion 1(MATE1) and MATE2K are responsible for the transport of metformin from the renal cells to the urine in tubule lumen [113]. Thus, it should be cautious to use metformin in patients with impaired liver or kidney function. Recently, it has been demonstrated that genetic polymorphisms in transporter genes play an important role in both metformin pharmacokinetics and pharmacodynamics [114, 115].

Of note, the steady state concentrations of metformin in plasma are very low. In an adult T2DM patient by oral administration of 1.5 2.5 g/day ( $\sim 30 \mathrm{mg} / \mathrm{kg} /$ day $)$, plasma concentration is approximately $10 \mu \mathrm{M}$ in plasma [105]. In rodent animals, usually 5 times injection dose (150 $\mathrm{mg} / \mathrm{kg}$, i.p.) or 10 times oral dose $(250 \sim 300 \mathrm{mg} / \mathrm{kg})$ of humans will achieve 5 10 $\mu \mathrm{M}$ which generate similar effects [116]. These low concentrations can hardly lead to acute activation of AMPK although gluconeogenesis is inhibited. One explanation is that metformin is a cation and transport to mitochondria slowly, but accumulates there to high concentrations (100 500 fold, i.e. 1 5 mM), which is sufficient for AMPK activation [116]. In keeping with this, the concentrations required for AMPK activation in vitro are at $\mathrm{mM}$ levels.

Concentrations of berberine that are effective in in vitro studies range between $10 \sim 100 \mu \mathrm{M}$, which are thousands of times greater than those normally attainable following oral ingestion in human [117]. Berberine has poor solubility in aqueous solution and its solubility at $37^{\circ} \mathrm{C}$ depends on $\mathrm{pH}$, which decreases with lowering $\mathrm{pH}$ and reaches maximum of $9.69 \pm 0.37 \mathrm{mM}$ in phosphate buffer $[118,119]$. It is absorbed from gastrointestinal tract with low efficiency. The maximum concentration $(\mathrm{Cm})$ of berberine in plasma is $12 \mathrm{nM}$ after the oral administration of $100 \mathrm{mg} / \mathrm{kg}$ in rats [120]. The $\mathrm{Cm}$ is $50 \mathrm{nM}$ at $15 \mathrm{~min}$ after the oral administration of $25 \mathrm{mg} / \mathrm{kg}$ in rats and the plasma concentration decreases rapidly within $12 \mathrm{~h}$ [121]. In humans, a single oral dose of $500 \mathrm{mg}$ berberine administration generates $0.07 \pm 0.01 \mathrm{nM}$ in plasma, while the $\mathrm{Cm}$ is $4.0 \pm 2.0 \mathrm{nM}$ after chronic administration of $15 \mathrm{mg} / \mathrm{kg}$ for three months [122]. Such low concentrations attained in vivo raise a question as to if they could take effect. It is possible that berberine might accumulate inside cells, similarly to metformin, to achieve the in vivo effects.

The low efficiency of berberine transport to blood is mostly accounted for by the poor oral bioavailability, which is determined by several factors [123]. First, drug self-aggregation decreases the solubility. Berberine tends to aggregate, especially in low $\mathrm{pH}$, which leads to poor absorption in stomach and upper small intestine [119]. Second, the permeability of berberine is low [118]. Third, berberine is a substrate of P-glycoprotein-mediated efflux in the intestine, which further limits its transport in the absorption direction [124]. $80 \%$ of berberine is metabolized in the liver and intestine by CYP2D6. These together define the difficulty in delivery of berberine. Therefore, to enhance the efficacy, it is imperative to enhance the bioavailability by modifying structure of the drug or enhancing permeation with additives.

\section{PROSPECTIVE}

Hyperglycaemia, hyperlipidemia, insulin resistance and obesity are collectively defined as metabolic syndrome (MetS), firstly termed by Haller and Hanefeld in 1975 [125]. These metabolic abnormalities are strongly interrelated, ameliorating one could benefit the others. Otherwise 
the culminating adverse outcome significantly increases risk of T2DM, CVD, and tumours [126]. Metformin has been used in clinics for years and its impacts on various metabolic disorders as mentioned above make it stand out in MetS therapies. In recent years, berberine is emerging as an attractive new agent in treating MetS, as it shares many features with metformin and more importantly, is also low cost. However, the poor oral bioavailability may limit its application [27]. Application of metformin in optimal dosage may also be prevented in OCT1 variant patients where adverse gastrointestinal reactions are observed [127]. In the case that is refractory or intolerable to metformin, berberine may be used as an alternative or additive agent to increase tolerance and minimize the side effects. In keeping with this, a recent study on a six months trial with 60 patients with T2DM randomly divided groups of berberine and metformin or metformin alone and better efficacy was observed in the combined treatment group [25]. It is postulated that the synergism action of berberine and metformin is attributed to similar anti-diabetic mechanisms in spite of different transporter and metabolism. Therefore, combination of these two drugs might allow reduction in dosage of each individual drugs to solve problems such as oral bioavailability of berberine and side effects of each alone.

\section{CONCLUSIONS}

Metformin and berberine shares many aspects in actions and mechanisms despite different structure. While metformin is the first line anti-diabetic drug, berberine is not extensively used in treatment of T2DM and MetS in Western countries although it is a nonprescriptive medicine and experimental studies show promising results. Few studies directly compare the efficacy of metformin and berberine in treating T2DM and MetS. Since the side effects of berberine are tolerable and controllable (usually gastrointestinal discomfort), clinical investigations to compare these two drugs are definitely feasible. Hopefully, more clinical investigation on the use of berberine will be conducted in the near future.

\section{Abbreviations}

AMPK, AMP-activated protein kinase; ATM, adipose tissue macrophages; EMT, epithelial and mesenchymal transition; HbA1c, hemoglobin A1c; IL-1 $\beta$, interleukin-1 $\beta$; IL-6, interleukin-6; LDL-c low density lipoprotein-cholesterol; LDLR, low density lipoprotein receptor; LKB1, liver kinase B1; MAPK, mitogenactivated protein kinase; MATE, multidrug and toxin extrusion; MetS, metabolic syndrome; mTOR, mammalian target of rapamycin; NAFLD, non-alcoholic fat liver disease; NASH, non-alcoholic steatohepatitis; NF- $\mathrm{B}$, nuclear factor-kappa B; OCT, organic cation transporter; PCSK9, proprotein convertase subtilisin/kexin type 9; PKC, protein kinase; PPAR $\gamma$, peroxisome proliferator- activated receptor gamma; $\mathrm{RAR} \beta$, retinoic acid receptor beta; T2DM, type 2 diabetes mellitus; TSC1, tuberous sclerosis complex 1; TSC2, tuberous sclerosis complex; UKPDS, the United Kingdom Prospective Diabetes Study.

\section{Author contributions}

HRW and CZ wrote mostly manuscript, YY and YL contributed to some writing and editing. DH and ZL made sure the information and literature cited are accurate and were responsible for final writing and editing.

\section{CONFLICTS OF INTEREST}

None.

\section{FUNDING}

This work was supported by National Natural Science Foundation of China (31660332, 81572753, 31460304, and 81460374 ) and by Jiangxi Entrepreneurship and Innovation Model Center grant by Jiangxi Bureau of Foreign Experts.

\section{REFERENCES}

1. Witters LA. The blooming of the French lilac. J Clin Invest. 2001; 108:1105-1107.

2. Thomas I, Gregg B. Metformin; a review of its history and future: from lilac to longevity. Pediatr Diabetes. 2017; 18:10-16.

3. Hundal RS, Inzucchi SE. Metformin: new understandings, new uses. Drugs. 2003; 63:1879-1894.

4. Xia X, Wang H, Niu X, Wang H, Liu Z, Liu Y, Qi Z, Wang S, Liu S, Liu S. Assessment of the anti-diarrhea function of compound Chinese herbal medicine Cangpo Oral Liquid. Afr J Tradit Complement Altern Med. 2014; 11:140-147.

5. Chang Y. [Effectiveness of berberine in bacillary dysentery] [Article in Chinese]. Zhonghua Nei Ke Za Zhi. 1959; 7:741-743.

6. Singh J, Kakkar P. Antihyperglycemic and antioxidant effect of Berberis aristata root extract and its role in regulating carbohydrate metabolism in diabetic rats. J Ethnopharmacol. 2009; 123:22-26.

7. Kumar A, Ekavali, Chopra K, Mukherjee M, Pottabathini R, Dhull DK. Current knowledge and pharmacological profile of berberine: An update. Eur J Pharmacol. 2015; 761:288-297.

8. Jiang XW, Zhang Y, Zhu YL, Zhang H, Lu K, Li FF, Peng HY. Effects of berberine gelatin on recurrent aphthous stomatitis: a randomized, placebo-controlled, double-blind trial in a Chinese cohort. Oral Surg Oral Med Oral Pathol Oral Radiol. 2013; 115:212-217.

9. Li HL, Han T, Liu RH, Zhang C, Chen HS, Zhang WD. Alkaloids from Corydalis saxicola and their anti-hepatitis B virus activity. Chem Biodivers. 2008; 5:777-783. 
10. Somogyi A. [Editorial comment: Diabetes complications] [Article in Hungarian]. Orv Hetil. 2011; 152:1143.

11. Sen S, Chakraborty R. Treatment and Diagnosis of Diabetes Mellitus and Its Complication: Advanced Approaches. Mini Rev Med Chem. 2015; 15:1132-1133.

12. DeFronzo RA. Lilly lecture 1987 . The triumvirate: betacell, muscle, liver. A collusion responsible for NIDDM. Diabetes. 1988; 37:667-687.

13. Jallut D, Golay A, Munger R, Frascarolo P, Schutz Y, Jequier E, Felber JP. Impaired glucose tolerance and diabetes in obesity: a 6-year follow-up study of glucose metabolism. Metabolism. 1990; 39:1068-1075.

14. Zimmet P, Whitehouse S, Alford F, Chisholm D. The relationship of insulin response to a glucose stimulus over a wide range of glucose tolerance. Diabetologia. 1978; $15: 23-27$.

15. Saad MF, Knowler WC, Pettitt DJ, Nelson RG, Mott $\mathrm{DM}$, Bennett PH. Sequential changes in serum insulin concentration during development of non-insulin-dependent diabetes. Lancet. 1989; 1:1356-1359.

16. Defronzo RA. Banting Lecture. From the triumvirate to the ominous octet: a new paradigm for the treatment of type 2 diabetes mellitus. Diabetes. 2009; 58:773-795.

17. Smith BK, Marcinko K, Desjardins EM, Lally JS, Ford RJ, Steinberg GR. Treatment of nonalcoholic fatty liver disease: role of AMPK. Am J Physiol Endocrinol Metab. 2016; 311:E730-E740.

18. Yang $\mathrm{X}, \mathrm{Xu} \mathrm{Z}$, Zhang C, Cai Z, Zhang J. Metformin, beyond an insulin sensitizer, targeting heart and pancreatic beta cells. Biochim Biophys Acta. 2017; 1863:1984-1990.

19. Coughlan KA, Valentine RJ, Ruderman NB, Saha AK. AMPK activation: a therapeutic target for type 2 diabetes? Diabetes Metab Syndr Obes. 2014; 7:241-253.

20. Lupi R, Del Guerra S, Fierabracci V, Marselli L, Novelli M, Patane G, Boggi U, Mosca F, Piro S, Del Prato S, Marchetti P. Lipotoxicity in human pancreatic islets and the protective effect of metformin. Diabetes. 2002; 51 Suppl 1:S134-137.

21. Lupi R, Del Guerra S, Tellini C, Giannarelli R, Coppelli A, Lorenzetti M, Carmellini M, Mosca F, Navalesi R, Marchetti P. The biguanide compound metformin prevents desensitization of human pancreatic islets induced by high glucose. Eur J Pharmacol. 1999; 364:205-209.

22. Pernicova I, Korbonits M. Metformin--mode of action and clinical implications for diabetes and cancer. Nat Rev Endocrinol. 2014; 10:143-156.

23. Madiraju AK, Erion DM, Rahimi Y, Zhang XM, Braddock DT, Albright RA, Prigaro BJ, Wood JL, Bhanot S, MacDonald MJ, Jurczak MJ, Camporez JP, Lee HY, et al. Metformin suppresses gluconeogenesis by inhibiting mitochondrial glycerophosphate dehydrogenase. Nature. 2014; 510:542-546.

24. He H, Ke R, Lin H, Ying Y, Liu D, Luo Z. Metformin, an old drug, brings a new era to cancer therapy. Cancer J. $2015 ; 21: 70-74$.
25. Pang B, Zhao LH, Zhou Q, Zhao TY, Wang H, Gu CJ, Tong XL. Application of berberine on treating type 2 diabetes mellitus. Int J Endocrinol. 2015; 2015:905749.

26. Chen QM, Xie MZ. [Studies on the hypoglycemic effect of Coptis chinensis and berberine] [Article in Chinese]. Yao Xue Xue Bao. 1986; 21:401-406.

27. Yin J, Xing H, Ye J. Efficacy of berberine in patients with type 2 diabetes mellitus. Metabolism. 2008; 57:712-717.

28. Zhang H, Wei J, Xue R, Wu JD, Zhao W, Wang ZZ, Wang SK, Zhou ZX, Song DQ, Wang YM, Pan HN, Kong WJ, Jiang JD. Berberine lowers blood glucose in type 2 diabetes mellitus patients through increasing insulin receptor expression. Metabolism. 2010; 59:285-292.

29. Lan J, Zhao Y, Dong F, Yan Z, Zheng W, Fan J, Sun G. Meta-analysis of the effect and safety of berberine in the treatment of type 2 diabetes mellitus, hyperlipemia and hypertension. J Ethnopharmacol. 2015; 161:69-81.

30. Kong WJ, Zhang H, Song DQ, Xue R, Zhao W, Wei J, Wang YM, Shan N, Zhou ZX, Yang P, You XF, Li ZR, Si SY, et al. Berberine reduces insulin resistance through protein kinase C-dependent up-regulation of insulin receptor expression. Metabolism. 2009; 58:109-119.

31. Xia X, Yan J, Shen Y, Tang K, Yin J, Zhang Y, Yang D, Liang $\mathrm{H}$, Ye J, Weng J. Berberine improves glucose metabolism in diabetic rats by inhibition of hepatic gluconeogenesis. PLoS One. 2011; 6:e16556.

32. Knowler WC, Fowler SE, Hamman RF, Christophi CA, Hoffman HJ, Brenneman AT, Brown-Friday JO, Goldberg R, Venditti E, Nathan DM, and Diabetes Prevention Program Research Group. 10-year follow-up of diabetes incidence and weight loss in the Diabetes Prevention Program Outcomes Study. Lancet. 2009; 374:1677-86.

33. Seifarth C, Schehler B, Schneider HJ. Effectiveness of metformin on weight loss in non-diabetic individuals with obesity. Exp Clin Endocrinol Diabetes. 2013; 121:27-31.

34. Le TA, Loomba R. Management of Non-alcoholic Fatty Liver Disease and Steatohepatitis. J Clin Exp Hepatol. 2012; 2:156-173.

35. Zhang Z, Zhang H, Li B, Meng X, Wang J, Zhang Y, Yao S, Ma Q, Jin L, Yang J, Wang W, Ning G. Berberine activates thermogenesis in white and brown adipose tissue. Nat Commun. 2014; 5:5493.

36. Jiang D, Wang D, Zhuang X, Wang Z, Ni Y, Chen S, Sun F. Berberine increases adipose triglyceride lipase in 3T3-L1 adipocytes through the AMPK pathway. Lipids Health Dis. 2016; 15:214.

37. Evans RM, Barish GD, Wang YX. PPARs and the complex journey to obesity. Nat Med. 2004; 10:355-361.

38. Huang C, Zhang Y, Gong Z, Sheng X, Li Z, Zhang W, Qin Y. Berberine inhibits 3T3-L1 adipocyte differentiation through the PPARgamma pathway. Biochem Biophys Res Commun. 2006; 348:571-578.

39. Brusq JM, Ancellin N, Grondin P, Guillard R, Martin S, Saintillan Y, Issandou M. Inhibition of lipid synthesis through activation of AMP kinase: an additional mechanism 
for the hypolipidemic effects of berberine. J Lipid Res. 2006; 47:1281-1288.

40. Ge Y, Zhang Y, Li R, Chen W, Li Y, Chen G. Berberine regulated Gck, G6pc, Pck1 and Srebp-1c expression and activated AMP-activated protein kinase in primary rat hepatocytes. Int J Biol Sci. 2011; 7:673-684.

41. Kim WS, Lee YS, Cha SH, Jeong HW, Choe SS, Lee MR, Oh GT, Park HS, Lee KU, Lane MD, Kim JB. Berberine improves lipid dysregulation in obesity by controlling central and peripheral AMPK activity. Am J Physiol Endocrinol Metab. 2009; 296:E812-819.

42. Zhao Z, Cheng X, Wang Y, Han R, Li L, Xiang T, He L, Long H, Zhu B, He Y. Metformin inhibits the IL-6-induced epithelial-mesenchymal transition and lung adenocarcinoma growth and metastasis. PLoS One. 2014; 9:e95884.

43. Chang X, Yan H, Fei J, Jiang M, Zhu H, Lu D, Gao X. Berberine reduces methylation of the MTTP promoter and alleviates fatty liver induced by a high-fat diet in rats. J Lipid Res. 2010; 51:2504-2515.

44. Zhou JY, Zhou SW, Zhang KB, Tang JL, Guang LX, Ying Y, Xu Y, Zhang L, Li DD. Chronic effects of berberine on blood, liver glucolipid metabolism and liver PPARs expression in diabetic hyperlipidemic rats. Biol Pharm Bull. 2008; 31:1169-1176.

45. Zhang X, Zhao Y, Zhang M, Pang X, Xu J, Kang C, Li M, Zhang C, Zhang Z, Zhang Y, Li X, Ning G, Zhao L. Structural changes of gut microbiota during berberinemediated prevention of obesity and insulin resistance in high-fat diet-fed rats. PLoS One. 2012; 7:e42529.

46. Zhang BJ, Xu D, Guo Y, Ping J, Chen LB, Wang H. Protection by and anti-oxidant mechanism of berberine against rat liver fibrosis induced by multiple hepatotoxic factors. Clin Exp Pharmacol Physiol. 2008; 35:303-309.

47. Di Pierro F, Villanova N, Agostini F, Marzocchi R, Soverini V, Marchesini G. Pilot study on the additive effects of berberine and oral type 2 diabetes agents for patients with suboptimal glycemic control. Diabetes Metab Syndr Obes. 2012; 5:213-217.

48. UK Prospective Diabetes Study (UKPDS) Group. Effect of intensive blood-glucose control with metformin on complications in overweight patients with type 2 diabetes (UKPDS 34). Lancet. 1998; 352:854-865.

49. Abbasi F, Chu JW, McLaughlin T, Lamendola C, Leary ET, Reaven GM. Effect of metformin treatment on multiple cardiovascular disease risk factors in patients with type 2 diabetes mellitus. Metabolism. 2004; 53:159-164.

50. Xu T, Brandmaier S, Messias AC, Herder C, Draisma HH, Demirkan A, Yu Z, Ried JS, Haller T, Heier M, Campillos M, Fobo G, Stark R, et al. Effects of metformin on metabolite profiles and LDL cholesterol in patients with type 2 diabetes. Diabetes Care. 2015; 38:1858-1867.

51. Ansell BJ, Watson KE, Fogelman AM. An evidencebased assessment of the NCEP Adult Treatment Panel II guidelines. National Cholesterol Education Program. JAMA. 1999; 282:2051-2057.
52. Marin-Neto JA, Maciel BC, Secches AL, Gallo Junior L. Cardiovascular effects of berberine in patients with severe congestive heart failure. Clin Cardiol. 1988; 11:253-260.

53. Kong W, Wei J, Abidi P, Lin M, Inaba S, Li C, Wang Y, Wang Z, Si S, Pan H, Wang S, Wu J, Wang Y, et al. Berberine is a novel cholesterol-lowering drug working through a unique mechanism distinct from statins. Nat Med. 2004; 10:1344-1351.

54. Abidi P, Zhou Y, Jiang JD, Liu J. Extracellular signal-regulated kinase-dependent stabilization of hepatic low-density lipoprotein receptor mRNA by herbal medicine berberine. Arterioscler Thromb Vasc Biol. 2005; 25:2170-2176.

55. Marazzi G, Cacciotti L, Pelliccia F, Iaia L, Volterrani M, Caminiti G, Sposato B, Massaro R, Grieco F, Rosano G. Long-term effects of nutraceuticals (berberine, red yeast rice, policosanol) in elderly hypercholesterolemic patients. Adv Ther. 2011; 28:1105-1113.

56. Li H, Dong B, Park SW, Lee HS, Chen W, Liu J. Hepatocyte nuclear factor 1alpha plays a critical role in PCSK9 gene transcription and regulation by the natural hypocholesterolemic compound berberine. J Biol Chem. 2009; 284:28885-28895.

57. Cameron J, Ranheim T, Kulseth MA, Leren TP, Berge KE. Berberine decreases PCSK9 expression in HepG2 cells. Atherosclerosis. 2008; 201:266-273.

58. Wang Y, Yi X, Ghanam K, Zhang S, Zhao T, Zhu X. Berberine decreases cholesterol levels in rats through multiple mechanisms, including inhibition of cholesterol absorption. Metabolism. 2014; 63:1167-1177.

59. Luo Z, Saha AK, Xiang X, Ruderman NB. AMPK, the metabolic syndrome and cancer. Trends Pharmacol Sci. 2005; 26:69-76.

60. Luo Z, Zang M, Guo W. AMPK as a metabolic tumor suppressor: control of metabolism and cell growth. Future Oncol. 2010; 6:457-470.

61. Evans JM, Donnelly LA, Emslie-Smith AM, Alessi DR, Morris AD. Metformin and reduced risk of cancer in diabetic patients. BMJ. 2005; 330:1304-1305.

62. Wan G, Yu X, Chen P, Wang X, Pan D, Wang X, Li L, Cai X, Cao F. Metformin therapy associated with survival benefit in lung cancer patients with diabetes. Oncotarget. 2016; 7:35437-35445. https://doi.org/10.18632/oncotarget.8881.

63. Cerullo M, Gani F, Chen SY, Canner J, Pawlik TM. Metformin Use Is Associated with Improved Survival in Patients Undergoing Resection for Pancreatic Cancer. J Gastrointest Surg. 2016; 20:1572-1580.

64. Cabello P, Pineda B, Tormo E, Lluch A, Eroles P. The Antitumor Effect of Metformin Is Mediated by miR-26a in Breast Cancer. Int J Mol Sci. 2016; 17.

65. Esteller M, Avizienyte E, Corn PG, Lothe RA, Baylin $\mathrm{SB}$, Aaltonen LA, Herman JG. Epigenetic inactivation of LKB1 in primary tumors associated with the Peutz-Jeghers syndrome. Oncogene. 2000; 19:164-168. 
66. Sun R, Li J, Wang B, Guo Y, Ma L, Quan X, Chu Z, Li T. Liver kinase $\mathrm{B} 1$ promoter $\mathrm{CpG}$ island methylation is related to lung cancer and smoking. Int J Clin Exp Med. 2015; 8:14070-14074.

67. Deepa SS, Zhou L, Ryu J, Wang C, Mao X, Li C, Zhang N, Musi N, DeFronzo RA, Liu F, Dong LQ. APPL1 mediates adiponectin-induced LKB1 cytosolic localization through the PP2A-PKCzeta signaling pathway. Mol Endocrinol. 2011; 25:1773-1785.

68. Zoncu R, Efeyan A, Sabatini DM. mTOR: from growth signal integration to cancer, diabetes and ageing. Nat Rev Mol Cell Biol. 2011; 12:21-35.

69. LoPiccolo J, Blumenthal GM, Bernstein WB, Dennis PA. Targeting the PI3K/Akt/mTOR pathway: effective combinations and clinical considerations. Drug Resist Updat. 2008; 11:32-50.

70. Garcia D, Shaw RJ. AMPK: Mechanisms of Cellular Energy Sensing and Restoration of Metabolic Balance. Mol Cell. 2017; 66:789-800.

71. Su K, Hu P, Wang X, Kuang C, Xiang Q, Yang F, Xiang J, Zhu S, Wei L, Zhang J. Tumor suppressor berberine binds VASP to inhibit cell migration in basal-like breast cancer. Oncotarget. 2016; 7:45849-45862. https://doi. org/10.18632/oncotarget.9968.

72. Wang J, Yang S, Cai X, Dong J, Chen Z, Wang R, Zhang S, Cao H, Lu D, Jin T, Nie Y, Hao J, Fan D. Berberine inhibits EGFR signaling and enhances the antitumor effects of EGFR inhibitors in gastric cancer. Oncotarget. 2016; 7:76076-76086. https://doi.org/10.18632/oncotarget.12589.

73. Kou Y, Li L, Li H, Tan Y, Li B, Wang K, Du B. Berberine suppressed epithelial mesenchymal transition through cross-talk regulation of PI3K/AKT, RARalpha/RARbeta in melanoma cells. Biochem Biophys Res Commun. 2016; 479:290-296.

74. Yang X, Huang N. Berberine induces selective apoptosis through the AMPKmediated mitochondrial/caspase pathway in hepatocellular carcinoma. Mol Med Rep. 2013; 8:505-510.

75. Pierpaoli E, Damiani E, Orlando F, Lucarini G, Bartozzi B, Lombardi P, Salvatore C, Geroni C, Donati A, Provinciali $\mathrm{M}$. Antiangiogenic and antitumor activities of berberine derivative NAX014 compound in a transgenic murine model of HER2/neu-positive mammary carcinoma. Carcinogenesis. 2015; 36:1169-1179.

76. Ho YT, Yang JS, Lu CC, Chiang JH, Li TC, Lin JJ, Lai KC, Liao CL, Lin JG, Chung JG. Berberine inhibits human tongue squamous carcinoma cancer tumor growth in a murine xenograft model. Phytomedicine. 2009; 16:887-890.

77. Zhao H, Halicka HD, Li J, Darzynkiewicz Z. Berberine suppresses gero-conversion from cell cycle arrest to senescence. Aging (Albany NY). 2013; 5:623-636. https:// doi.org/10.18632/aging.100593.

78. Patil JB, Kim J, Jayaprakasha GK. Berberine induces apoptosis in breast cancer cells (MCF-7) through mitochondrial-dependent pathway. Eur J Pharmacol. 2010; 645:70-78.

79. Yu YN, Yu TC, Zhao HJ, Sun TT, Chen HM, Chen HY, An HF, Weng YR, Yu J, Li M, Qin WX, Ma X, Shen N, et al. Berberine may rescue Fusobacterium nucleatuminduced colorectal tumorigenesis by modulating the tumor microenvironment. Oncotarget. 2015; 6:32013-32026. https://doi.org/10.18632/oncotarget.5166.

80. Dertsiz L, Ozbilim G, Kayisli Y, Gokhan GA, Demircan A, Kayisli UA. Differential expression of VASP in normal lung tissue and lung adenocarcinomas. Thorax. 2005; 60:576-581.

81. Hirsch HA, Iliopoulos D, Tsichlis PN, Struhl K. Metformin selectively targets cancer stem cells, and acts together with chemotherapy to block tumor growth and prolong remission. Cancer Res. 2009; 69:7507-7511.

82. Lin H, Li N, He H, Ying Y, Sunkara S, Luo L, Lv N, Huang D, Luo Z. AMPK Inhibits the Stimulatory Effects of TGFbeta on Smad2/3 Activity, Cell Migration, and Epithelial-toMesenchymal Transition. Mol Pharmacol. 2015; 88:1062-1071.

83. Chu SC, Yu CC, Hsu LS, Chen KS, Su MY, Chen PN. Berberine reverses epithelial-to-mesenchymal transition and inhibits metastasis and tumor-induced angiogenesis in human cervical cancer cells. Mol Pharmacol. 2014; 86:609-623.

84. Zou K, Li Z, Zhang Y, Zhang HY, Li B, Zhu WL, Shi JY, Jia Q, Li YM. Advances in the study of berberine and its derivatives: a focus on anti-inflammatory and anti-tumor effects in the digestive system. Acta Pharmacol Sin. 2017; 38:157-167.

85. Zhou H, Mineshita S. The effect of berberine chloride on experimental colitis in rats in vivo and in vitro. J Pharmacol Exp Ther. 2000; 294:822-829.

86. Koh SJ, Kim JM, Kim IK, Ko SH, Kim JS. Antiinflammatory mechanism of metformin and its effects in intestinal inflammation and colitis-associated colon cancer. J Gastroenterol Hepatol. 2014; 29:502-510.

87. Mbeunkui F, Johann DJ Jr. Cancer and the tumor microenvironment: a review of an essential relationship. Cancer Chemother Pharmacol. 2009; 63:571-582.

88. Lewis CE, Pollard JW. Distinct role of macrophages in different tumor microenvironments. Cancer Res. 2006; 66:605-612.

89. Liu J, Lin PC, Zhou BP. Inflammation fuels tumor progress and metastasis. Curr Pharm Des. 2015; 21:3032-3040.

90. Saisho Y. Metformin and Inflammation: Its Potential Beyond Glucose-lowering Effect. Endocr Metab Immune Disord Drug Targets. 2015; 15:196-205.

91. Zhou H, Feng L, Xu F, Sun Y, Ma Y, Zhang X, Liu H, Xu G, Wu X, Shen Y, Sun Y, Wu X, Xu Q. Berberine inhibits palmitate-induced NLRP3 inflammasome activation by triggering autophagy in macrophages: A new mechanism linking berberine to insulin resistance improvement. Biomed Pharmacother. 2017; 89:864-874.

92. Ye L, Liang S, Guo C, Yu X, Zhao J, Zhang H, Shang W. Inhibition of M1 macrophage activation in adipose tissue by berberine improves insulin resistance. Life Sci. 2016; 166:82-91. 
93. Mansuy-Aubert V, Zhou QL, Xie X, Gong Z, Huang JY, Khan AR, Aubert G, Candelaria K, Thomas S, Shin DJ, Booth S, Baig SM, Bilal A, et al. Imbalance between neutrophil elastase and its inhibitor alpha1-antitrypsin in obesity alters insulin sensitivity, inflammation, and energy expenditure. Cell Metab. 2013; 17:534-548.

94. Fujisaka S, Usui I, Bukhari A, Ikutani M, Oya T, Kanatani Y, Tsuneyama K, Nagai Y, Takatsu K, Urakaze M, Kobayashi M, Tobe K. Regulatory mechanisms for adipose tissue M1 and M2 macrophages in diet-induced obese mice. Diabetes. 2009; 58:2574-2582.

95. Wellen KE, Hotamisligil GS. Obesity-induced inflammatory changes in adipose tissue. J Clin Invest. 2003; 112:1785-1788.

96. Hyun B, Shin S, Lee A, Lee S, Song Y, Ha NJ, Cho KH, Kim K. Metformin Down-regulates TNF-alpha Secretion via Suppression of Scavenger Receptors in Macrophages. Immune Netw. 2013; 13:123-132.

97. Chen S, Zhu X, Lai X, Xiao T, Wen A, Zhang J. Combined cancer therapy with non-conventional drugs: all roads lead to AMPK. Mini Rev Med Chem. 2014; 14:642-654.

98. Zhou G, Myers R, Li Y, Chen Y, Shen X, Fenyk-Melody J, Wu M, Ventre J, Doebber T, Fujii N, Musi N, Hirshman MF, Goodyear LJ, Moller DE. Role of AMP-activated protein kinase in mechanism of metformin action. J Clin Invest. 2001; 108:1167-1174.

99. Owen MR, Doran E, Halestrap AP. Evidence that metformin exerts its anti-diabetic effects through inhibition of complex 1 of the mitochondrial respiratory chain. Biochem J. 2000; 348 Pt 3:607-614.

100. Foretz M, Hebrard S, Leclerc J, Zarrinpashneh E, Soty M, Mithieux G, Sakamoto K, Andreelli F, Viollet B. Metformin inhibits hepatic gluconeogenesis in mice independently of the LKB1/AMPK pathway via a decrease in hepatic energy state. J Clin Invest. 2010; 120:2355-2369.

101. Perriello G, Misericordia P, Volpi E, Santucci A, Santucci C, Ferrannini E, Ventura MM, Santeusanio F, Brunetti P, Bolli GB. Acute antihyperglycemic mechanisms of metformin in NIDDM. Evidence for suppression of lipid oxidation and hepatic glucose production. Diabetes. 1994; 43:920-928.

102. Turner N, Li JY, Gosby A, To SW, Cheng Z, Miyoshi H, Taketo MM, Cooney GJ, Kraegen EW, James DE, Hu LH, Li J, Ye JM. Berberine and its more biologically available derivative, dihydroberberine, inhibit mitochondrial respiratory complex I: a mechanism for the action of berberine to activate AMP-activated protein kinase and improve insulin action. Diabetes. 2008; 57:1414-1418.

103. Xu M, Xiao Y, Yin J, Hou W, Yu X, Shen L, Liu F, Wei L, Jia W. Berberine promotes glucose consumption independently of AMP-activated protein kinase activation. PLoS One. 2014; 9:e103702.

104. Gong L, Goswami S, Giacomini KM, Altman RB, Klein TE. Metformin pathways: pharmacokinetics and pharmacodynamics. Pharmacogenet Genomics. 2012; 22:820-827.
105. Graham GG, Punt J, Arora M, Day RO, Doogue MP, Duong JK, Furlong TJ, Greenfield JR, Greenup LC, Kirkpatrick CM, Ray JE, Timmins P, Williams KM. Clinical pharmacokinetics of metformin. Clin Pharmacokinet. 2011; 50:81-98.

106. Beckmann R. [Absorption, distribution in the organism and elimination of metformin] [Article in German]. Diabetologia. 1969; 5:318-324.

107. Chen L, Pawlikowski B, Schlessinger A, More SS, Stryke D, Johns SJ, Portman MA, Chen E, Ferrin TE, Sali A, Giacomini KM. Role of organic cation transporter 3 (SLC22A3) and its missense variants in the pharmacologic action of metformin. Pharmacogenet Genomics. 2010; 20:687-699.

108. Shu Y, Sheardown SA, Brown C, Owen RP, Zhang S, Castro RA, Ianculescu AG, Yue L, Lo JC, Burchard EG, Brett CM, Giacomini KM. Effect of genetic variation in the organic cation transporter 1 (OCT1) on metformin action. J Clin Invest. 2007; 117:1422-1431.

109. Nies AT, Koepsell H, Winter S, Burk O, Klein K, Kerb R, Zanger UM, Keppler D, Schwab M, Schaeffeler E. Expression of organic cation transporters OCT1 (SLC22A1) and OCT3 (SLC22A3) is affected by genetic factors and cholestasis in human liver. Hepatology. 2009; 50:1227-1240.

110. Galuska D, Nolte LA, Zierath JR, Wallberg-Henriksson H. Effect of metformin on insulin-stimulated glucose transport in isolated skeletal muscle obtained from patients with NIDDM. Diabetologia. 1994; 37:826-832.

111. Yuan H, Hu Y, Zhu Y, Zhang Y, Luo C, Li Z, Wen T, Zhuang W, Zou J, Hong L, Zhang X, Hisatome I, Yamamoto T, Cheng J. Metformin ameliorates high uric acid-induced insulin resistance in skeletal muscle cells. Mol Cell Endocrinol. 2017; 443:138-145.

112. Banerjee J, Bruckbauer A, Zemel MB. Activation of the AMPK/Sirt1 pathway by a leucine-metformin combination increases insulin sensitivity in skeletal muscle, and stimulates glucose and lipid metabolism and increases life span in Caenorhabditis elegans. Metabolism. 2016; 65:1679-1691.

113. Morrissey KM, Stocker SL, Chen EC, Castro RA, Brett CM, Giacomini KM. The Effect of Nizatidine, a MATE2K Selective Inhibitor, on the Pharmacokinetics and Pharmacodynamics of Metformin in Healthy Volunteers. Clin Pharmacokinet. 2016; 55:495-506.

114. Todd JN, Florez JC. An update on the pharmacogenomics of metformin: progress, problems and potential. Pharmacogenomics. 2014; 15:529-539.

115. Niu N, Liu T, Cairns J, Ly RC, Tan X, Deng M, Fridley BL, Kalari KR, Abo RP, Jenkins G, Batzler A, Carlson EE, Barman P, et al. Metformin pharmacogenomics: a genomewide association study to identify genetic and epigenetic biomarkers involved in metformin anticancer response using human lymphoblastoid cell lines. Hum Mol Genet. 2016; 25:4819-4834.

116. Chandel NS, Avizonis D, Reczek CR, Weinberg SE, Menz S, Neuhaus R, Christian S, Haegebarth A, Algire C, Pollak 
M. Are Metformin Doses Used in Murine Cancer Models Clinically Relevant? Cell Metab. 2016; 23:569-570.

117. Liu CS, Zheng YR, Zhang YF, Long XY. Research progress on berberine with a special focus on its oral bioavailability. Fitoterapia. 2016; 109:274-282.

118. Battu SK, Repka MA, Maddineni S, Chittiboyina AG, Avery MA, Majumdar S. Physicochemical characterization of berberine chloride: a perspective in the development of a solution dosage form for oral delivery. AAPS PharmSciTech. 2010; 11:1466-1475.

119. Spinozzi S, Colliva C, Camborata C, Roberti M, Ianni C, Neri F, Calvarese C, Lisotti A, Mazzella G, Roda A. Berberine and its metabolites: relationship between physicochemical properties and plasma levels after administration to human subjects. J Nat Prod. 2014; 77:766-772.

120. Liu Y, Hao H, Xie H, Lv H, Liu C, Wang G. Oxidative demethylenation and subsequent glucuronidation are the major metabolic pathways of berberine in rats. J Pharm Sci. 2009; 98:4391-4401.

121. Gong Z, Chen Y, Zhang R, Wang Y, Guo Y, Yang Q, Zhang H, Dong Y, Weng X, Gao S, Zhu X. Pharmacokinetic comparison of berberine in rat plasma after oral administration of berberine hydrochloride in normal and post inflammation irritable bowel syndrome rats. Int J Mol Sci. $2014 ; 15: 456-467$.
122. Hua W, Ding L, Chen Y, Gong B, He J, Xu G. Determination of berberine in human plasma by liquid chromatographyelectrospray ionization-mass spectrometry. J Pharm Biomed Anal. 2007; 44:931-937.

123. Zhang J, Zhou F, Lu M, Ji W, Niu F, Zha W, Wu X, Hao H, Wang G. Pharmacokinetics-pharmacology disconnection of herbal medicines and its potential solutions with cellular pharmacokinetic-pharmacodynamic strategy. Curr Drug Metab. 2012; 13:558-576.

124. Bansal T, Mishra G, Jaggi M, Khar RK, Talegaonkar S. Effect of P-glycoprotein inhibitor, verapamil, on oral bioavailability and pharmacokinetics of irinotecan in rats. Eur J Pharm Sci. 2009; 36:580-590.

125. O'Neill S, O'Driscoll L. Metabolic syndrome: a closer look at the growing epidemic and its associated pathologies. Obes Rev. 2015; 16:1-12.

126. Sookoian S, Pirola CJ. Metabolic syndrome: from the genetics to the pathophysiology. Curr Hypertens Rep. 2011; 13:149-157.

127. Dujic T, Causevic A, Bego T, Malenica M, Velija-Asimi Z, Pearson ER, Semiz S. Organic cation transporter 1 variants and gastrointestinal side effects of metformin in patients with Type 2 diabetes. Diabet Med. 2016; 33:511-514. 